\title{
Accessory spleen after splenectomy mimicking adrenal tumor: a case report
}

\author{
Gunaghui Zang ${ }^{1}$, Bingzheng Dong ${ }^{1}$, Guangyuan Zhu ${ }^{1}$, Xiangzheng Qiu ${ }^{1}$, Yan Zhao ${ }^{2}$ \\ ${ }^{1}$ Department of Urology, ${ }^{2}$ Department of Cardiology, Xuzhou Central Hospital, Xuzhou, China \\ Correspondence to: Yan Zhao. Department of Cardiology, Xuzhou Central Hospital, 199 South Jiefang Road, Xuzhou, China. Email: zgh_zy@163.com.
}

\begin{abstract}
Accessory spleen is a congenital anomaly, those asymptomatic generally do not need surgical intervention. Retroperitoneal heterotopic accessory spleens are often misdiagnosed, especially in cases that have undergone splenectomy for various reasons. In these cases, most patients are received unnecessary resection for misdiagnosed as adrenal gland tumors, ganglioblastomas or paragangliomas preoperatively. We report on a case of accessory spleen mimicking a left adrenal tumor. A 47-year-old man who had undergone splenectomy 25 years ago was referred to our department because of hypertension, CT scan revealed a mass about $4 \mathrm{~cm}$ in the left adrenal gland. The mass was confirmed nonfunctional through hormonal evaluation of the adrenal gland. We found the mass was not originated from the adrenal gland intraoperation even they were close together. Histopathologic examination of the surgical specimen revealed an accessory spleen. The differences between the case and other accessory spleen patients include a history of hypertension, the location of the mass and a history of splenectomy, and these also are the main reasons for our misdiagnosis. This case remind us that an accessory spleen should be considered for the biochemically inactive mass in left adrenal area, even the splenectomy has been performed before.
\end{abstract}

Keywords: Accessory spleen; adrenal Tumor; misdiagnosed; laparoscopic adrenalectomy; case report

Submitted Feb 17, 2020. Accepted for publication Jul 10, 2020.

doi: $10.21037 /$ tcr-20-1067

View this article at: http://dx.doi.org/10.21037/tcr-20-1067

\section{Introduction}

Accessory spleen is a relatively common congenital defect characterized by a separated ectopic splenic parenchyma, and is found in about $16 \%$ of the population (1). The accessory spleen located in retroperitoneal space is easily misdiagnosed as adrenal mass, ganglioblastomas or paragangliomas, especially for patients with hypertension. Accessory spleens may subsequently undergone compensatory enlargement after splenectomy. In this situation, it is more confusing, and more likely to be misdiagnosed. With the advances of imaging techniques, such as CT scan and MRI, increasing number of retroperitoneal tumors have been found, however, it is still difficult to distinguish adrenal tumor from accessory spleen preoperative by imaging in some cases (2). We present the following article in accordance with the CARE reporting checklist (available at http://dx.doi.org/10.21037/ tcr-20-1067).

\section{Case presentation}

In Dec. 2, 2019, a 47-year-old patient was admitted to the department of cardiology due to hypertension, and referred to urology because a $4 \mathrm{~cm}$ tumor was detected in the left adrenal gland by abdominal CT scan (Figures 1,2). The patient had undergone splenectomy 25 years ago for thrombocytopenia, and had a history of hypertension for 4 years. Family and psycho-social history were denied. In fact, the mass was detected 2 years ago about $2 \mathrm{~cm}$ but no treatment was adopted. Considering the mass was doubled in 2 years, and was located in the adrenal gland, adrenal cancer could not be excluded based on the results of CT scan, we scheduled a retroperitoneal laparoscopic exploration after two weeks of dilatation and treatment of hypertension although the mass was confirmed nonfunctional through hormonal evaluation of the adrenal gland. The blood pressure of the patient fluctuated around 

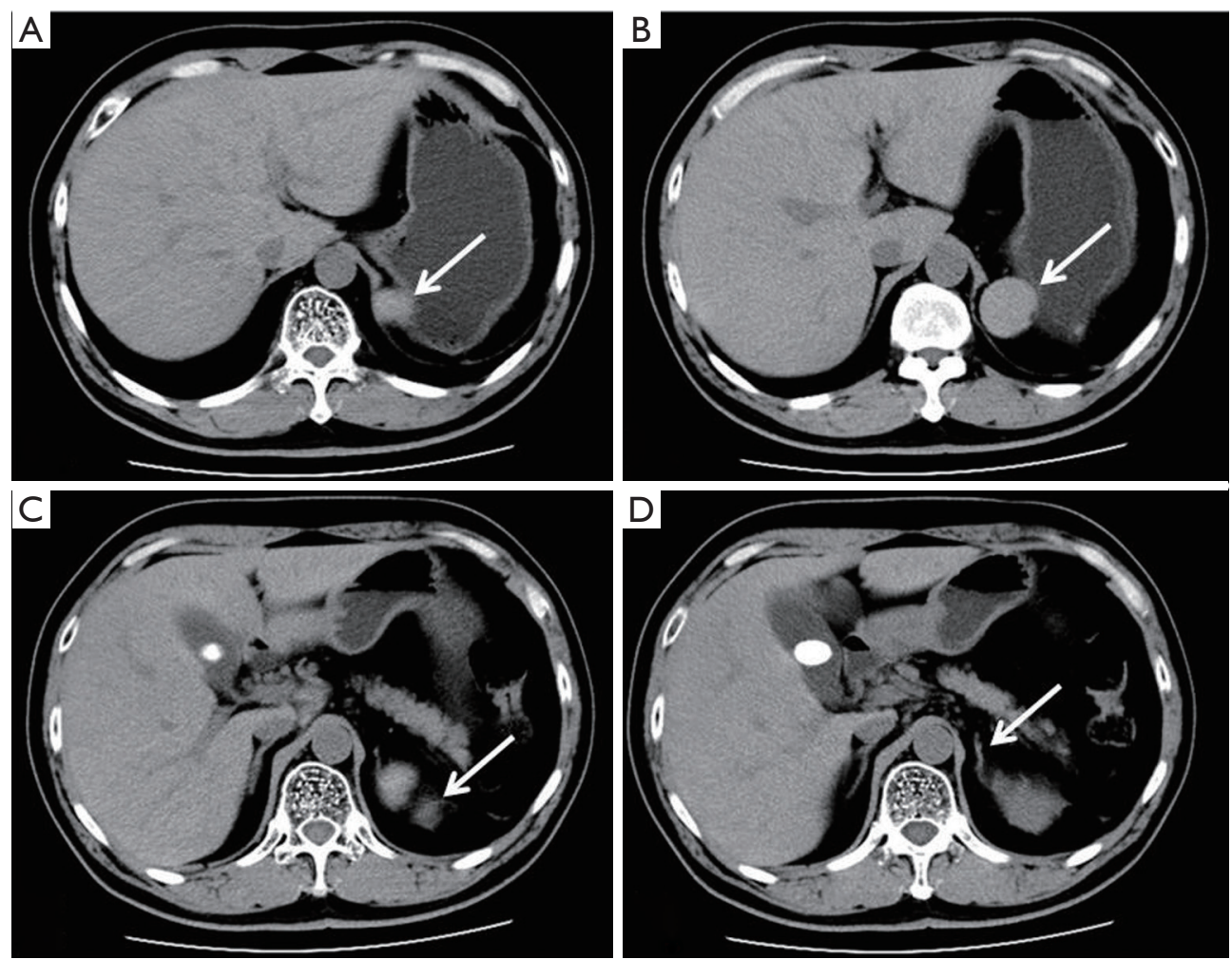

Figure 1 Abdominal CT scan. (A,B) CT reveals a retroperitoneal mass (white arrows) with a similar CT value to the hepar; (C) the white arrow indicates the upper pole of the left kidney; (D) the white arrow indicates the left adrenal gland.
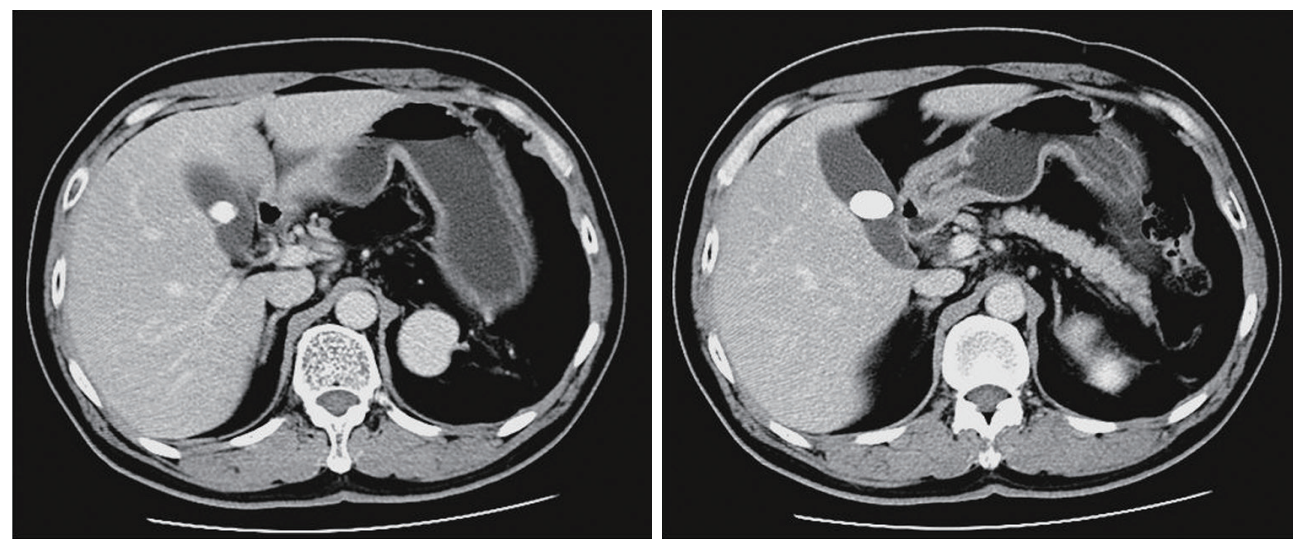

Figure 2 Arterial phase of contrast enhanced computed tomography image.

$160 / 90 \mathrm{mmHg}$ pre-admission, and we adjust it stable around $130 / 80 \mathrm{mmHg}$ preoperation. Intraoperative, we found the mass adhered to the lateral peritoneum closely but was not originated from the left adrenal gland (Figure 3). We resected the tumor completely, and the histological results of the specimen indicated that it was an accessory spleen (Figure 4). Through 2 months follow-up, we found that there were no complications occurred, and the patient's blood pressure did not decrease compared to that of preadmission. The diagnosis and treatment procedure were shown in the timeline (Figure 5).

We confirm that all figures are originals in this report, 

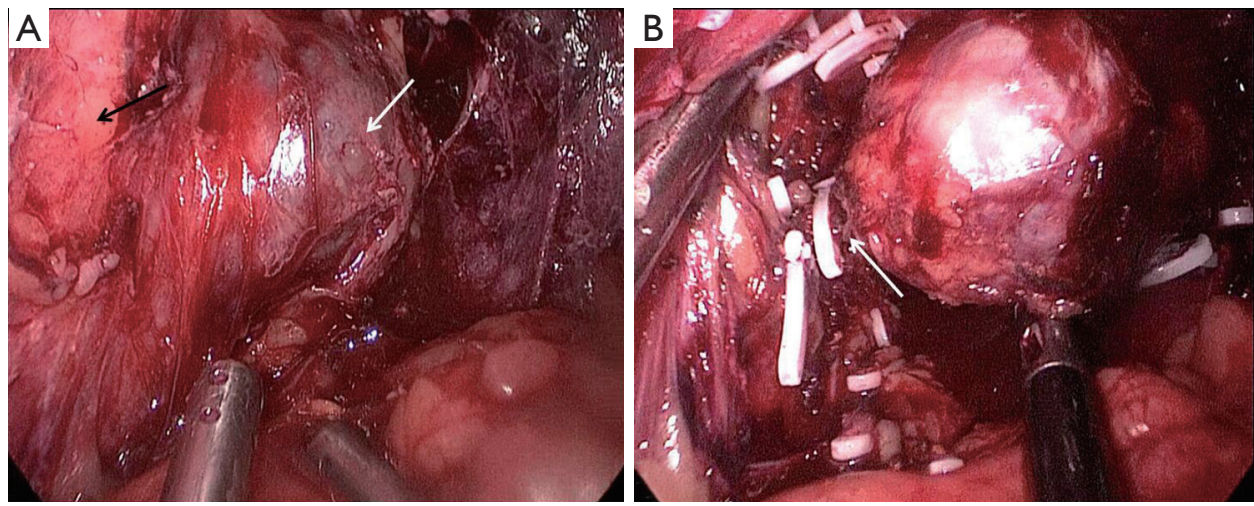

Figure 3 Surgical findings. (A) The black arrow indicates the lateral peritoneum. The white arrow indicates the mass adhered to the lateral peritoneum closely; (B) The white arrow indicates the nutrient vessels of the mass.

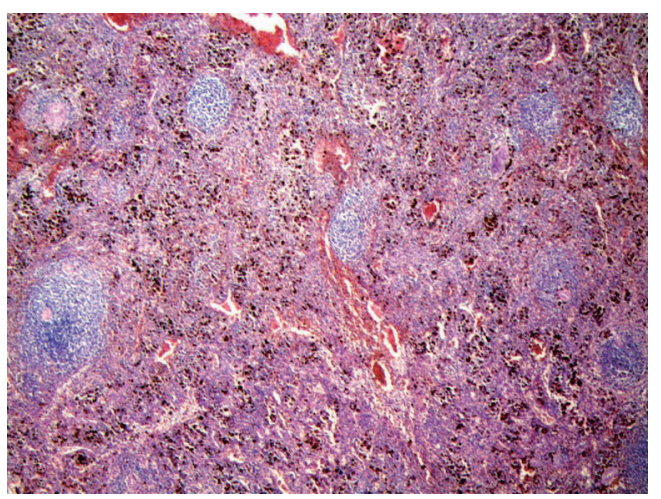

Figure 4 Histologic magnification revealed accessory splenic tissue. Pathological findings $(\times 200)$. and the accompanying images, were provided by the patient. All procedures performed in studies involving human participants were in accordance with the ethical standards of the institutional and/or national research committee(s) and with the Helsinki Declaration (as revised in 2013). Written informed consent was obtained from the patient.

\section{Discussion}

Accessory spleen is a congenital anomaly, almost locate in the splenic hilum $(75 \%)$ and the pancreatic tail (20\%) (3), the others may locate in omentum, small intestine, mesentery and testis. They are often mimicked

Translational Cancer Research

Timeline and duration of diagnosis and treatment

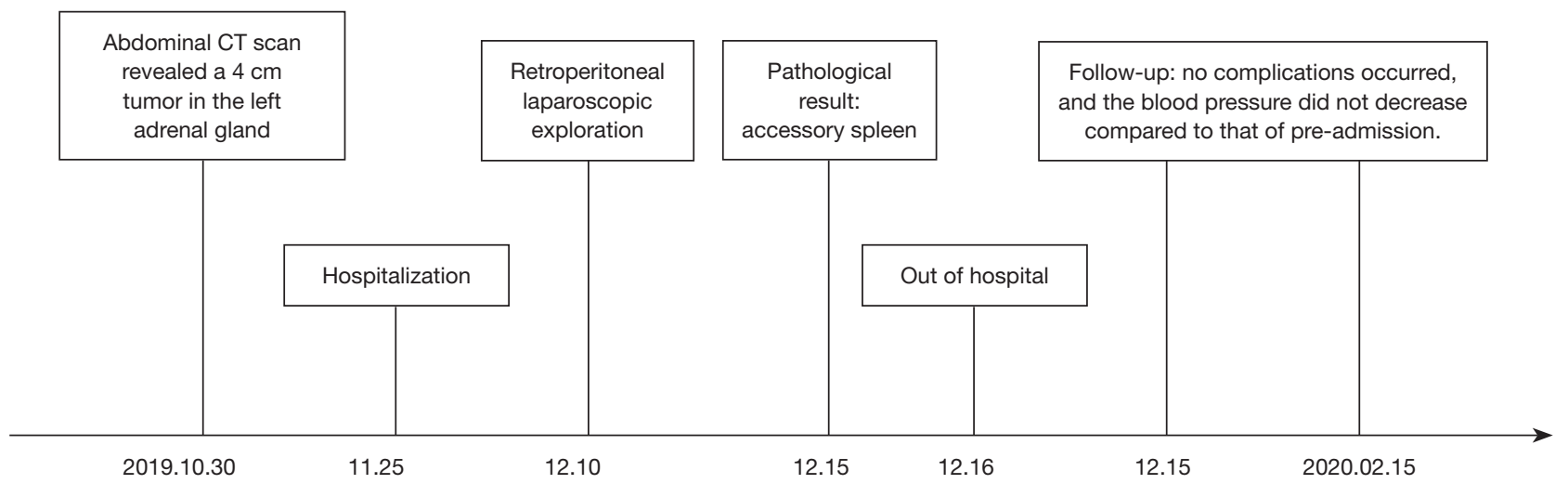

Figure 5 Timeline and duration of diagnosis and treatment. 
pancreatic or gastrointestinal tumors, adrenal masses, and even testicular tumors (4). Most accessory spleens are asymptomatic and are diagnosed as an incidental finding, so-called 'incidentalomas', during health examination. The larger accessory spleen may present with symptoms of compression, gastrointestinal tract pulling, and pain, shock or other symptoms may also occur when torsion, necrosis, hemorrhage happened (5).

An asymptomatic accessory spleen does not need resect for the low possibility of malignancy, unfortunately, most accessory spleens are difficult to be confirmed preoperatively (6), and are confirmed only after resection. The primary reason for this situation is that CT/MRI imaging cannot provide a conclusive diagnosis (7). Most accessory spleen presents heterogeneous enhancement during the first minute after bolus injection of contrast due to different blood flow rates through the cords of the red and white pulp (8), the case we reported present homogeneous density during the arterial phase maybe due to untimely shot we took. Scintigraphy with Tc$99 \mathrm{~m}$ phytate is the most useful method of evaluating an accessory spleen (9), however, another important reason for this situation is that clinicians do not pay enough attention to accessory spleen, scintigraphy is rarely used immediately after the incidental detection of a mass (6).

The reason we misdiagnosed the mass as an adrenal tumor was mainly because the patient had undergone splenectomy 25 years ago, and had a history of hypertension, and the mass was in contact with the adrenal gland radiologically. This case reminds us that we should be aware of the possibility of accessory spleens when a left nonfunctional adrenal tumor is suspected by imaging techniques, even the splenectomy have been performed before.

\section{Acknowledgments}

Funding: The work was supported by the National Natural Science Foundation of China (81774089), Innovative and Entrepreneurial Doctor Project of Jiangsu Province (ZXYYSCBS-201703) and Jiangsu Province Medical Innovation Team Project (No.CXTD2016-48).

\section{Footnote}

Reporting Checklist: The authors have completed the CARE reporting checklist. Available at http://dx.doi.org/10.21037/ tcr-20-1067
Conflicts of Interest: All authors have completed the ICMJE uniform disclosure form (available at http://dx.doi. org/10.21037/tcr-20-1067). All authors report grants from National Natural Science Foundation of China, grants from Innovative and Entrepreneurial Doctor Project of Jiangsu Province, grants from Jiangsu Province Medical Innovation Team Project, during the conduct of the study.

Ethical statement: The authors are accountable for all aspects of the work in ensuring that questions related to the accuracy or integrity of any part of the work are appropriately investigated and resolved. All procedures performed in studies involving human participants were in accordance with the ethical standards of the institutional and/or national research committee(s) and with the Helsinki Declaration (as revised in 2013). Written informed consent was obtained from the patient.

Open Access Statement: This is an Open Access article distributed in accordance with the Creative Commons Attribution-NonCommercial-NoDerivs 4.0 International License (CC BY-NC-ND 4.0), which permits the noncommercial replication and distribution of the article with the strict proviso that no changes or edits are made and the original work is properly cited (including links to both the formal publication through the relevant DOI and the license). See: https://creativecommons.org/licenses/by-nc-nd/4.0/.

\section{References}

1. Palumbo V, Mannino M, Teodoro M, et al. An extremely rare case of an oversized accessory spleen: case report and review of the literature. BMC Surg 2019;19:45.

2. Riley DS, Barber MS, Kienle GS, et al. CARE guidelines for case reports: explanation and elaboration document. J Clin Epidemiol 2017;89:218-35.

3. Farvacque G, De Chaisemartin C. Accessory spleen mimicking an intra-abdominal tumour. ANZ J Surg 2019;89:E448-9.

4. Tsuchiya N, Sato K, Shimoda N, et al. An accessory spleen mimicking a nonfunctional adrenal tumor: a potential pitfall in the diagnosis of a left adrenal tumor. Urol Int 2000;65:226-8.

5. Wacha M, Danis J, Wayand W. Laparoscopic resection of an accessory spleen in a patient with chronic lower abdominal pain. Surg Endosc 2002;16:1242-3.

6. Matsuzawa H, Munakata S, Momose H, et al. A 
Progressive Huge Accessory Spleen in the Greater Omentum. Case Rep Gastroenterol 2019; 13:539-43.

7. Rosenblatt GS, Luthringer DJ, Fuchs GJ. Enlargement of accessory spleen after splenectomy can mimic a solitary adrenal tumor. Urology 2010;75:561-2.

Cite this article as: Zang G, Dong B, Zhu G, Qiu X, Zhao Y. Accessory spleen after splenectomy mimicking adrenal tumor: a case report. Transl Cancer Res 2020;9(9):5679-5683. doi: 10.21037/ tcr-20-1067
8. Rashid SA. Accessory Spleen: Prevalence and Multidetector CT Appearance. Malays J Med Sci 2014;21:18-23.

9. Nishiguchi S, Habu D, Ishizu H, et al. Accessory spleen in the pelvis diagnosed by Tc-99m phytate scintigraphy. Ann Nucl Med 2001;15:263-5. 